\title{
DEBATE
}

\section{Organochlorine residues pose surprisingly high dietary risks}

\section{M Benbrook}

J Epidemiol Community Health 2002;56:822-823

All US government pesticide residue datasets show that persistent organochlorine $(\mathrm{OC})$ insecticide residues are surprisingly common in certain foods despite being off the market for over 20 years. Residues of dieldrin, in particular, pose substantial risks in certain root crops. About $60 \%$ of the samples of organic vegetables found to contain pesticides are contaminated with OCs. Government regulators, organic certifiers, and the food industry will face growing pressure to develop methods to identify $O C$ contaminated fields and avoid production of crops prone to assimilating $\mathrm{OC}$ residues in harvested foodstuffs.
See end of article for author's affiliations

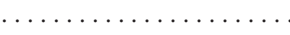

Correspondence to: Charles M Benbrook 5085 Upper Pack River Road, Sandpoint, Idaho 83864, USA;

benbrook@hillnet.com
$\mathrm{R}$ esidues of persistent organochlorine (OC) insecticides are present in a surprisingly high percentage of the food supply, as documented by Schafer and Kegley. ${ }^{1}$ Their findings are reinforced by similar frequencies and levels of OCs found in foods tested by the USDA through its Pesticide Data Program (PDP). In the US Department of Agriculture (USDA) data, the frequency of residues of banned OCs is particularly high in squashes, spinach, and carrots, while still used OCs (such as endosulfan and dicofol) are most commonly found in green beans, spinach, strawberries, and cantaloupes (see table 9 in Groth et $\left.a l^{2}\right)$.

As part of work for Consumers Union on the implementation of the "Food Quality Protection Act," a "toxicity index" (TI) was developed to rank the risks posed by pesticide residues in the diet ( see methodology in reference 2 ). The TI is driven by the percentage of samples testing positive for a given food, the mean residue level, and the acute and chronic mammalian toxicity of the pesticide. Accordingly, TI values are useful for comparing the pesticide risks associated with the consumption of a given amount of a given food, compared with the same amount of other foods, or of the same food grown elsewhere and containing a different mix of residues.

Pesticide specific TI values for all foods tested by USDA-PDP from 1994-1999 have been calculated by food and country of origin. Residues of OCs account for about 5\% of total TI summed across all food-country combinations. In some foods OC residues dominate aggregate TI values, in particular summer and winter squash, carrots, grapes, and cantaloupe. For example, in 1998 US grown frozen winter squash, dieldrin residues were found in $78 \%$ of samples tested, at a mean level of $0.032 \mathrm{ppm}$, leading to a TI value of 3168 , which accounted for $94 \%$ of total TI across all residues found that year in that food. In general, Consumers Union considers any food-pesticide combination with a TI value over 100 to be a "risk driver"; very few combinations have TI values over 1000 (see table 5 in reference 2 ).

OC residues are a far bigger problem for producers of organic food than conventional food. Most consumers associate organic foods with no pesticide applications, and hence no residues, despite the fact that organic certifiers emphasise that "organic" on a label is not a pesticide free claim. Consumers are half right in their expectations, in that most organic foods that test positive for a pesticide are never directly and knowingly sprayed. Rather, drift, contaminated irrigation water, and bound OC residues in the soil account for most of the residues found. ${ }^{3}$ Analysis of three residue datasets showed that about one quarter of the samples of organically labelled fresh produce contained residues, compared with about three quarters of conventional samples. The percentage of organic samples testing positive for one or more residues decreases by about half, however, when OC residues where excluded from organic samples. Excluding OC residues makes only a modest difference in the percentage of conventional samples testing positive (see tables 1 and 2 in reference 2).

Especially for dieldrin (the most toxic of the OCs commonly found in food), the "safe" level for infants and children would be well below the limit of detection, based on modern risk assessment methods and current US law, a point made effectively by Shafer and Kegley. ${ }^{1}$ Fortunately, OC residues are uncommon in several key children's foods including milk and apples. The highest TI value for a pesticide found in milk by the USDAPDP was just 2.2, based on $17 \%$ of samples found to contain on average $0.002 \mathrm{ppm}$ of DDE.

A few OCs are still registered today and one is widely used and often found in a wide variety of foods-endosulfan. Lindane continues to be one of the most widely used products to treat head lice in children. This OC use is one of the most worrisome of all contemporary pesticide use patterns and is under intense regulatory review.

Most OC residues present in food at levels of toxicological concern are found in a small number of crops that have the capacity to both extract bound OC residues from soil and translocate and accumulate them in their edible portions. Fortunately, this is an exposure pathway

Abbreviations: $\mathrm{OC}$, organochlorine; $\mathrm{Tl}$, toxicity index 
that can be largely eliminated at modest cost. The testing of fields for OC contamination has to be done only once and is affordable. Fields above recognised benchmark levels should not be planted to the handful of crops known to take up these residues. ${ }^{4}$

If the evidence linking very low OC exposures to endocrine system mediated developmental abnormalities continues to strengthen, regulators will be forced to revise downward the "action levels" and/or tolerances sanctioning the presence of OC residues in food. The food industry will seek out produce free of OC residues, a corporate policy adopted years ago by the leading baby food company in the world, Gerber Products. Organic farmers will probably be in the forefront of further efforts to avoid growing crops susceptible to OC contamination in soils with bound residues, a step already taken by some growers and organic certifiers.

\section{Author's affiliations}

C M Benbrook, Benbrook Consulting Services, Idaho, USA

\section{REFERENCES}

1 Schafer, KS, Kegley SE. Persistent toxic chemicals in the US food supply. J Epidemiol Community Health 2002;56:813-17.

2 Groth E, Benbrook C, Lutz K. Update: Pesticides in children's foods. New York: Consumers Union, 2000. (http://www.ecologic-ipm.com/ findings_CU.html\#reports)

3 Baker BP, Benbrook CM, Groth E, et al. Pesticide residues in conventional, integrated pest management (IPM)-grown and organic foods: insights from three US data sets. Food Addit Contam 2002; 19:427-46.

4 Oregon Tilth. Certified organic standards manual. Oregon: Oregon Tilth, 2001. (http://www.tilth.org/Publications/OTCOStandards.pdf). 